\title{
Endoscopic Management of Migrated Intra Uterine Device in Sub-Saharan Health Setting Area. Our Experience about Seventeen Cases
}

\author{
Traoré Youssouf ${ }^{*}$, Kanté Ibrahim², Sima Mamadou², Ongoiba Ibrahima², Coulibaly Ahmadou², \\ Dicko Birama ${ }^{3}$, Bocoum Amadou${ }^{1}$, Kodio Souma², Théra Tiounkani², \\ Téguété Ibrahima ${ }^{1}$, Traoré Mamadou ${ }^{2}$
}

\author{
${ }^{1}$ Department of Gynecology and Obstetrics of Gabriel Touré Teaching Hospital, Bamako, Mali \\ ${ }^{2}$ Department of Gynecology and Obstetrics of Point “G” Teaching Hospital, Bamako, Mali \\ ${ }^{3}$ Department of Forensic Medicine of Bamako University, Bamako, Mali \\ Email: *dryoussouf.traore@gmail.com
}

How to cite this paper: Youssouf, T., Ibrahim, K., Mamadou, S., Ibrahima, O., Ahmadou, C., Birama, D., Amadou, B., Souma, K., Tiounkani, T., Ibrahima, T. and Mamadou, T. (2018) Endoscopic Management of Migrated Intra Uterine Device in Sub-Saharan Health Setting Area. Our Experience about Seventeen Cases. Surgical Science, 9, 17-23.

https://doi.org/10.4236/ss.2018.91003

Received: November 15, 2017

Accepted: January 5, 2018

Published: January 8, 2018

Copyright $\odot 2018$ by authors and Scientific Research Publishing Inc. This work is licensed under the Creative Commons Attribution International License (CC BY 4.0).

http://creativecommons.org/licenses/by/4.0/

\begin{abstract}
Intra uterine device migration is a relatively rare event. The migration of the IUD in the surrounded viscera can be managed by endoscopy approach. Objectives: We reported our experience to determine the epidemiologic characteristics of patients that presented migrated IUD, to report clinical aspects and describe the laparoscopic management. Method: We conducted a descriptive and prospective survey from January 1st, 2014 to October 31, 2016. That survey took place in the department of gynecology and obstetrics of Point $G$ Teaching hospital, Bamako, Mali. Population study concerned patients with intra uterine device complications. Statistic tests used have been $\mathrm{X}^{2}$ or Fisher test according their application conditions. $P<0.05$ was considered statistically significant. Results: Seventeen patients were included. Mean age of patients is 29 years with extremes of 13 years and 44 years. The main reference incitement of patients were perforation of the uterus and pelvis pain $(27.8 \%$ for each), misplaced IUD (22.3\%). Complications observed were intra uterine device migrated in to the bladder ( 1 case), in the abdomen (10 cases), in the ovary ( 2 cases) and in the uterine tuba ( 1 case). Three perforations were done without migration in to surrounded viscera. We used endoscopic surgery among all of them. But in one case we switched endoscopy method in to laparotomy because of important intra peritoneal bleeding to end the management of the patient. No death occurred and mean duration of the stay of hospitalization was 2 days. Conclusion: IUD migration is a scarce event. All the surrounded viscera can be the site of its migration. The management of that complication is usually done by endoscopy method.
\end{abstract}




\section{Keywords}

IUD Migration, Bladder, Pain, Endoscopy Surgery, Mali

\section{Introduction}

One of the most widely contraceptive methods used all over the world is the intra uterine device (IUD) [1] [2] [3], especially in developing countries. In Mali since many years, contraceptives with long duration of action are used because their safe utilization. Secondly they permit as to improve health of women as to improve contraceptive prevalence in our country. IUD constitutes one of the most efficient modern contraceptives with Pearl indice low than 1 to 100 women year [4]. Its insertion is usually a simple and safe [5] process in the gynecology practice. However, this method has some side effects like menstrual bleeding, pelvis pain, infection and uterine perforation [6] that is a rare but serious complication of modern contraceptive using [4]. After uterus perforation IUD migrates into several surrounding organs especially bladder, sigmoid colon.

The management of the misplaced of IUD can be done by many ways including laparotomy or endoscopy.

We reported our experience about laparoscopic management of the complications of migrated IUD and compared our results to that of the literature.

\section{Objective}

The purpose of this study was to determine the epidemiologic characteristics of patients that presented migrated IUD, to report clinical aspects and describe the laparoscopic management.

\section{Material and Method}

\subsection{Study Setting}

That survey took place in the department of gynecology and obstetrics of Point $\mathrm{G}$ Teaching hospital that is one of the referral centers in Bamako for the management of complications of modern contraceptive methods.

Since 2004, laparoscopic surgery is performed in this service for the management of some gynecology diseases.

\subsection{Type of Survey and Sampling}

We conducted a descriptive and prospective survey from January 1st, 2014 to October 31, 2016. Population study concerned patients with intra uterine device complications.

Inclusion Criteria: all the cases of perforated (migrated or no) intra uterine device managed by endoscopy.

Exclusion criteria: were patients with complications that have not been managed by endoscopy approach. 
Data about age of patients, reasons of consultation, types of health workers who inserted IUD, complications of IUD and moment of IUD insertion were collected from registries of hospitalization, surgical reports, and admissions records.

Calculations were performed using SPSS version 20.0 (SPSS Inc, Chicago, IL). Data have been analyzed using $\mathrm{X}^{2}$ or Fisher test according their application conditions $P<0.05$ was considered statistically significant.

After counseling informed consent has been obtained from patients before IUD insertion and when complications occurred for the management of the endoscopic management. The Ethics committee of the Faculty of Medicine, Pharmacy, and Dentistry at the University of Bamako, Mali approved this study.

\section{Results}

\subsection{Epidemiological and Clinical Aspects}

Seventeen patients were included. Table 1 that describes characteristics of the patients show mean age of patients is 29 years with extremes of 13 years and 44 years. The main reference incitement of patients were perforation of the uterus and pelvis pain (27.8\% for each), misplaced IUD (22.3\%). Regarding patients antecedents we noted three patients that had antecedent of cesarean and one received cesarean plus salpingectomy that was indicated for ectopic pregnancy. In $77.8 \%$ (14 cases), there had no surgical antecedent in our patients.

Most of IUD was inserted by midwives (64.7\%). The intra uterine insertion was post placental IUD insertion in 4 cases (22.2\%), interval IUD method in 12 cases $(66.7 \%)$.

Several complications were observed like shown in the Table 2. The mostly occurred during the 12 first months after IUD insertion (64.7).

Table 1. Characteristics and clinical aspects of the patients having misplaced IUD and managed by laparoscopy.

\begin{tabular}{|c|c|c|c|}
\hline \multicolumn{4}{|c|}{ Characteristics and clinical aspects } \\
\hline & $\mathrm{n}$ & $(\%)$ & $P$ \\
\hline \multicolumn{4}{|l|}{ Reason of consultation } \\
\hline Uterine Perforation & 5 & $(29.4)$ & \multirow{4}{*}{0.050} \\
\hline Pain & 5 & $(29.4)$ & \\
\hline Migration into bladder or abdomen & 3 & $(17.6)$ & \\
\hline IUD String disappearance & 4 & $(23.6)$ & \\
\hline \multicolumn{4}{|l|}{ Age of patients (yrs) } \\
\hline [13 - 19] & 1 & $(5.9)$ & \multirow{3}{*}{0.001} \\
\hline$[20-29]$ & 9 & $(52.9)$ & \\
\hline$[30-45]$ & 7 & $(41.2)$ & \\
\hline \multicolumn{4}{|c|}{ Types of health workers who inserted the IUD } \\
\hline Physicians & 6 & $(35.3)$ & \multirow{2}{*}{0.000} \\
\hline Midwives & 11 & $(64.7)$ & \\
\hline
\end{tabular}


Table 2. Relation between complications, types of health workers, moment of IUD insertion and periods among the 17 th patients.

\begin{tabular}{cccc}
\hline & \multicolumn{2}{c}{ IUD uterine perforation } & \\
\cline { 2 - 3 } & $\begin{array}{c}\text { Without migration } \\
\mathrm{n}(\%)\end{array}$ & $\begin{array}{c}\text { With migration } \\
\mathrm{n}(\%)\end{array}$ & $P$ value \\
Type of health workers $(\mathrm{n}=\mathbf{1 7})$ & & & \\
Physicians & $1(5.9)$ & $5(29.4)$ & 0.000 \\
Midwives & $2(11.8)$ & $9(52.9)$ & \\
Delay between insertion & & & 0.000 \\
and complications $(\mathrm{n}=17)$ & $1(5.9)$ & $10(58.8)$ & \\
$<12$ months & $2(11.8)$ & $2(11.8)$ & \\
Between 12 and 24 months & $0(00.0)$ & $2(11.8)$ & \\
$>24$ months & & & \\
Moment of IUD insertion ( $\mathbf{n}=17)$ & $1(5.9)$ & $3(17.6)$ & \\
Post placental insertion & $2(11.8)$ & $10(58.8)$ & \\
Interval IUD insertion & $0(00.0)$ & $1(5.9)$ & \\
Post abortion IUD insertion & & & \\
\hline
\end{tabular}

On the seventeen complications of IUD insertion uterine perforation without IUD migration has been noted in 3 cases again 14 migrated IUD. Rates of migration of the IUD and the organs where they migrated are variable. Thus, intra uterine device migrated in to the bladder ( 1 case), in the abdomen (10 cases), in the ovary ( 2 cases) and in the uterine tuba ( 1 case).

\subsection{Management}

Regarding the management of our patients, we used endoscopic surgery among all of them. Because of important bleeding, we switch endoscopic approach by classic laparotomy to end the management of one patient. It was about the case of migrated IUD in the uterine tuba with important abdominal bleeding.

\section{Discussion}

\subsection{Limitations of the Study}

Our study met some limitations concerning the price of endoscopic management in our service that is more expensive than classic laparotomy and the fewest experience of our endoscopic practice. Finally, some patients have been managed in other service. All these limitations can explain that the number of the IUD complications managed in our service during that period is low. However, we believe that these limitations didn't affect negatively the quality of this study that is rare in our health low setting area.

\subsection{Clinical Characteristics of Patients}

Intra uterine device is a safe [5], effective and reversible method of long-term contraception. In our country it is a mode of contraception that is mostly liked by women. Its widely use is explaining by its low cost and complications rates [7]. In the Table 1 that describes characteristics of the patients we can observe 
that mean age of our patients is 29 years with extremes of 13 years and 44 years. It is about women who are in active genital period activity.

The main reference incitement of patients were perforation of the uterus and pelvis pain (27.8\% for each), misplaced IUD (22.3\%). Migration of IUD has been suspected after the disappearance of the string of the IUD or occurrence of pain. However, most of our patients had no symptom; so for them the diagnosis was made after sonography [2] or plain X ray of abdomen [8].

Regarding patients antecedents we noted three patients had antecedent of cesarean and one received cesarean plus salpingectomy that was indicated for ectopic pregnancy.

According to the policy of ministry of health of our country to promote contraception in Mali, midwives have been training to insert IUD. Then, most of IUD has been inserted by midwives (64.7\%). The intra uterine insertion was post placental insertion in 4 cases (22.2\%), interval IUD method in 12 cases (66.7\%).

Table 2 shows complications that were observed in our survey. All the cases concerned uterus perforation with or without IUD migration. Literature review underlines variable rates of migration of the IUD into surrounded viscera. Authors reported some complications related to IUD insertion [2] [6] [9]. Kassab [10] in a publication realized in 1999, reported 165 cases of IUD migration. In his study different migrated sites are mentioned especially omentum (45), rectosigmoid, peritoneum (44), bladder (23). Thus, several surveys reported this kind of complications [8] [11]. Thus in our survey, intra uterine device migrated in to the bladder ( 1 case), in the abdomen (10 cases), in the ovary ( 2 cases) and in the uterine tuba ( 1 case). The most common reported places for this migration were the omentum, rectosigmoid colon, peritoneum and bladder and nearby viscera [12] [13] [14]. In our study we didn't have omentum or rectosigmoid IUD migration. No study in the literature reported IUD migration in the tuba of uterus. IUD migration in to the bladder looks more frequent than others [1].

Period between insertion of the IUD and the diagnosis of the misplaced of IUD is variable. The complications in our study mostly occurred during the 12 first months after IUD insertion.

\subsection{Management}

Regarding the literature, minimally invasive methods such as laparoscopy [15] [16] or cystoscopy are frequently preferred for the treatment [17] [18]. However the management of misplaced IUD still remains controversial and no consensus opinion exists. Some in the literature suggests that the translocated IUD's should be removed electively as complications like adhesions and bowel obstruction has been reported and removal should be done as soon as the diagnosis is made [6]. In our experience, we undertook management as soon as the diagnosis of the complication done. So for the management of our seventeen patients, we used endoscopic surgery. But in one case we converted because of difficulties classic laparotomy to end the management of the patient. It was about the case of migrated IUD (in Figure 1) in the uterine tuba with important abdominal bleeding. 


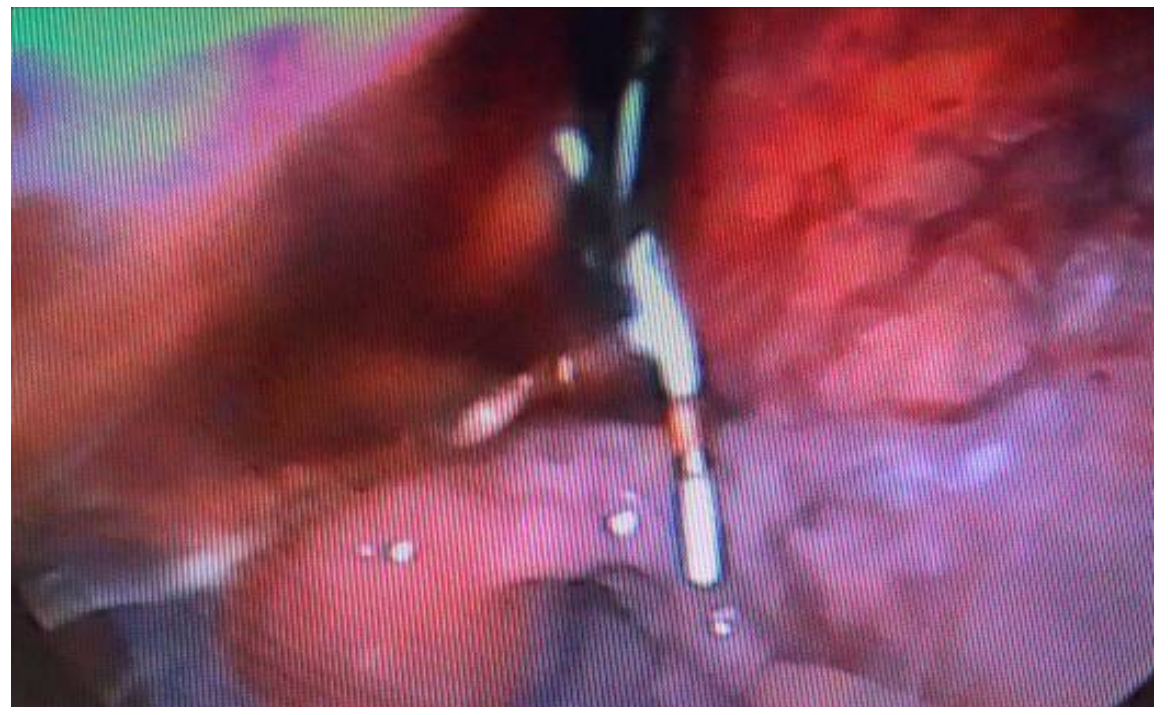

Figure 1. Endoscopic view of migrated IUD.

This trend is observed in Krishna [6] study where laparoscopic removal was possible in 7 of 9 cases of translocated IUD's. When IUD migrated in to bladder, cystoscopy can be first done [1].

However this method has some limits because only a small part of IUD is often seen. We didn't use cystoscopy to manage the case of IUUD migration into the bladder in our survey.

We agree with most of the authors [6] [16] that think that laparoscopy is invaluable in management of misplaced IUD. This method is associated with comfort, minimal hospital stay and early recovery and hence it is recommended as the preferred method for removal of misplaced IUD's [6]. After endoscopic surgery, no death occurred in our study and mean duration of the stay of hospitalization was 2 days confirming necessity to extend this management approach in all the four teaching hospitals of Bamako.

\section{Conclusion}

Misplaced of IUD is a rare event. Migrated sites are often peritoneum and the bladder. We reported two rare sites migrations that are the ovary wall and the uterus tuba. Their managements are usually successfully performed by endoscopy surgery. Prognosis of patients is well after endoscopy approach for management of IUD migrated out from uterus cavity.

\section{References}

[1] Atabekoğlu, C., Yalçin, I., Taşkin, S., Kahraman, K. and Sönmezer, M. (2012) Endoscopic Management of Migrated Intrauterine Device to the Bladder. International Medecine and Applied Science, 1, 48-49. https://doi.org/10.1556/IMAS.4.2012.1.8

[2] Mseddi, A.M., Ben Mefteh, I., Hadj Slimane, M., Hamza, M., Fourati, H., Derbel, M., Rebai, N., Gassara, H., Bouassida, M., Chaabène, K. and Mhiri, M.N. (2017) Intra Uterine Device Migrated into the Bladder. J.I.M. Sfax, 26, 58-61. 
[3] Kallat, A., Ibrahimi, A., Fahsi, O., El Sayegh, H., Iken, A., Benslimane, L. and Nouini, Y. (2017) Intra Uterine Device : About a Rare Complication and Literature Review. The Pan African Medical Journal, 27, 1-3.

[4] Lachiri, B., Hafidi, M.R., Zazi, A., Fagouri, H., Kouach, J. and Rahali, D.M. (2014) Migratory IUD: Report of Two Cases and Review of the Literature. The Pan African Medical Journal, 19, 361-364.

[5] Tepper, N.K., Curtis, K.M., Nanda, K. and Jamieson, J.D. (2016) Safety of Intrauterine Devices among Women with HIV: A Systematic Review. Contraception, 6, 713-724. https://doi.org/10.1016/j.contraception.2016.06.011

[6] Dahiya, K., Duhan, N., Nanda, S. and Lakra, P. (2010) Misplaced Intrauterine Device (IUD): The Endoscopic Management. JSAFOG, 2, 137-139.

https://doi.org/10.5005/jp-journals-10006-1082

[7] Sano, M., Nemoto, K., Miura, T. and Suzuki, Y. (2017) Endoscopic Treatment of Intrauterine Device Migration into the Bladder with Stone Formation. Journal of Endourology, 3, 105-107. https://doi.org/10.1089/cren.2017.0038

[8] Sawant, A., Kasat, G.V., Kumar, V., Pawar, P., Tamhankar, A. and Kapadnis, L. (2015) Endoscopic Removal of Intrauterine Contraceptive Device Embedded into Detrusor Muscle of Urinary Bladder: Our Experience of Two Cases. International Journal of Reproduction, Contraception, Obstetrics and Gynecology, 6, 2096-2099. https://doi.org/10.18203/2320-1770.ijrcog20151328

[9] Bhowate, P., Bhargava, A. and Jaiswa, A. (2016) Laparoscopic Management of Perforated Copper " $\mathrm{T}$ ” in Sigmoid Colon-Two Stage Approach. International Journal of Surgical International Journal of Surgery Cases, 2, 6-7.

[10] Kassab, B. and Audra, P. (1999) The Migrating Intrauterine Devices. Case Report and Review of Literature. Contraception, Fertilite, Sexualite, 27, 696-700.

[11] Gunbey, H.P., Sayit, A.T., Idilman, I.S. and Aksoy, O. (2014) Migration of Intrauterine Devices with Radiological Findings: Report on Two Case. BMJ Case Reports, 10, 1-3.

[12] Shariaghdas, F., Mohammad, A. and Abidi, H. (2007) Laparoscopic Removal of a Migrated Intrauterine Device. Urology Journal, 4, 177-179.

[13] Ozgun, M.T., Batukan, C., Serin, I.S., Ozcelik, B., Basbug, M. and Dolanbay, M. (2007) Surgical Management of Intra-Abdominal Mislocated Intrauterine Devices. Contraception, 75, 96-100. https://doi.org/10.1016/j.contraception.2006.09.011

[14] Bierman, A., Lefel, O., Segev, Y. and Lavie, O. (2010) Laparoscopic Removal of an Intrauterine Device Following Colon Perforation. JSLS, 14, 456-458. https://doi.org/10.4293/108680810X12924466006963

[15] Kaislasuo, J., Suhonen, S., Gissler, L., Lahteenmaki, P. and Heikinheimo, O. (2013) Uterus Perforation Caused by Intrauterine Devices: Clinical Course and Treatment. (2013) Human Reproduction, 28, 1546-1551. https://doi.org/10.1093/humrep/det074

[16] Heinberg, E.M., McCoy, T.W. and Pasic, R. (2008) The Perforated Intrauterine Device: Endoscopic Retrieval. JSLS, 12, 97-100.

[17] Mustafa, M. (2009) Erosion of an Intrauterine Contraceptive Device through the Bladder Wall Causing Calculus: Management and Review of the Literature. Urologia Internationalis, 3, 370-371. https://doi.org/10.1159/000209376

[18] Istanbulluoglu, M.O., et al. (2008) Bladder Perforation Related to Intrauterine Device. Journal of the Chinese Medical Association, 6, 207-209.

https://doi.org/10.1016/S1726-4901(08)70105-9 